\title{
Production, characterization and bioinformatics analysis of L-asparaginase from a new Stenotrophomonas maltophilia EMCC2297 soil isolate
}

\author{
Nada A. Abdelrazek ${ }^{10}$, Walid F. Elkhatib ${ }^{2,3}$, Marwa M. Raafat ${ }^{1}\left[\right.$ and Mohammad M. Aboulwafa ${ }^{3 *}$ (i)
}

\begin{abstract}
An exhaustive screening program was applied for scoring a promising L-asparaginase producing-isolate. The recovered isolate was identified biochemically and molecularly and its L-asparaginase productivity was optimized experimentally and by Response Surface Methodology. The produced enzyme was characterized experimentally for its catalytic properties and by bioinformatics analysis for its immunogenicity. The promising L-asparaginase producing-isolate was selected from 722 recovered isolates and identified as Stenotrophomonas maltophilia and deposited at Microbiological Resources Centre (Cairo Mircen) under the code EMCC2297. This isolate produces both intracellular (type I) and extracellular (type II) L-asparaginases with about 4.7 fold higher extracellular L-asparaginase productivity. Bioinformatics analysis revealed clustering of Stenotrophomonas maltophilia L-asparaginase with those of Pseudomonas species and considerable closeness to the two commercially available L-asparaginases of E. coli and Erwinia chrysanthemi. Fourteen antigenic regions are predicted for Stenotrophomonas maltophilia L-asparaginase versus 16 and 18 antigenic regions for the Erwinia chrysanthemi and E. coli L-asparaginases. Type II L-asparaginase productivity of the test isolate reached $4.7 \mathrm{IU} / \mathrm{ml} / \mathrm{h}$ and exhibited maximum activity with no metal ion requirement at $37^{\circ} \mathrm{C}, \mathrm{pH} 8.6,40 \mathrm{mM}$ asparagine concentration and could tolerate $\mathrm{NaCl}$ concentration up to $500 \mathrm{mM}$ and retain residual activity of $55 \%$ at $70{ }^{\circ} \mathrm{C}$ after half an hour treatment period. Application both of random mutation by gamma irradiation and Response Surface Methodology that determined $38.11^{\circ} \mathrm{C}, 6.89 \mathrm{pH}, 19.85 \mathrm{~h}$ and $179.15 \mathrm{rpm}$ as optimum process parameters could improve the isolate L-asparaginase productivity. Maximum production of about $8 \mathrm{IU} / \mathrm{ml} / \mathrm{h}$ was obtained with $0.4 \%$ dextrose, $0.1 \%$ yeast extract and $10 \mathrm{mM}$ magnesium sulphate. In conclusion L-asparaginase of the recovered Stenotrophomonas maltophilia EMCC2297 isolate has characters enabling it to be used for medical therapeutic application.
\end{abstract}

Keywords: L-asparaginase, Stenotrophomonas maltophilia, Production optimization, Characterization, Response Surface Methodology

\section{Introduction}

$\mathrm{L}$-asparaginase is a therapeutic enzyme used for the treatment of acute lymphocytic leukemia (Sinha et al. 2013).

\footnotetext{
*Correspondence: maboulwafa@yahoo.com; maboulwafa@pharma.asu.edu. eg

${ }^{3}$ Department of Microbiology and Immunology, Faculty of Pharmacy, Ain Shams University, African Union Organization St., Abbassia, Cairo 11566, Egypt

Full list of author information is available at the end of the article
}

This enzyme is present in many bacteria and plants but not in mankind and it has a crucial role in storage and transport of nitrogen required for protein biosynthesis. $\mathrm{L}$-asparaginase is synthesized at a slow rate in malignant cells as a result of their reduced capability to synthesize L-asparagine synthetase as compared to normal cells. Thus applying $\mathrm{L}$-asparaginase to tumor cells can deplete its content of $\mathrm{L}$-asparagine rendering them unable to synthesize protein as well as RNA and DNA and inducing 
apoptosis in these cells (Bansal et al. 2012). L-asparaginase is used in food industry to prevent the formation of acrylamide (carcinogenic toxicant) (Krishnapura et al. 2016) in food products manufactured at temperatures exceeding $100{ }^{\circ} \mathrm{C}$. Additionally, the amount of asparagine in leukemic patients and food materials can be detected by this enzyme (Batool et al. 2016). Microbial L-asparaginases are marketed for therapeutic applications under the brand names Kidrolase ${ }^{\circledR}$, Elspar ${ }^{\circledR}$ and for food applications under the commercial name Acrylaway ${ }^{\circledR}$ and PreventASe ${ }^{\circledR}$ (Krishnapura et al. 2016). In this article we succeeded to recover a bacterial soil isolate, Stenotrophomonas maltophilia EMCC2297, with promising L-asparaginase productivity. As revealed by bioinformatics analysis, the L-asparaginase of this isolate is less immunogenic than those of E. coli and Erwinia chrysanthemi, the commercially available ones. In this study, Stenotrophomonas maltophilia isolate recovered in this study was improved by gamma mutation and the production of the resultant variant of L-asparaginase was optimized by RSM experimental design and laboratory experiments to be introduced as a candidate for $\mathrm{L}$-asparaginase of medical and pharmaceutical use as antileukemic agent.

\section{Materials and methods Chemicals}

Unless otherwise stated the chemicals applied in this study were obtained from, (ADWIC) chemicals, Abuzaabal, Egypt. The source of $\mathrm{L}$-asparagine monohydrate was from AppliChem GmbH, Darmstadt, Germany.

\section{Isolate recovery from soil sample and qualitative assessment of L-asparaginase production}

Screening of 722 recovered isolates from different soil samples resulted in the scoring of an isolate with promising production capability for L-asparaginase as assessed qualitatively using the method described by Izadpanah et al. (2014). The applied method relied on the detection of pink zone surrounding L-asparaginase bacterial producer colonies on modified M9 agar medium containing $1 \% \mathrm{w} / \mathrm{v}$ asparagine and phenol red as indicator.

\section{Preparation of inoculum, production and quantitative assay of L-asparaginase by the selected recovered isolate} Both inoculum preparation and L-asparaginase production by the test isolate were carried out in $250 \mathrm{ml}$ Erlenmeyer flasks containing M9 with $1 \% \mathrm{w} / \mathrm{v}$ asparagine (20 $\mathrm{ml}$ in case of inoculum preparation and $50 \mathrm{ml}$ in case of L-asparaginase production condition). In both cases incubation was carried out at $37^{\circ} \mathrm{C}$ and $180 \mathrm{rpm}$ for $24 \mathrm{~h}$. The inoculum size used in the production condition was $2 \% \mathrm{v} / \mathrm{v}$ from adjusted growth at O.D ${ }_{600 \mathrm{~nm}}$ of 1.0 (Mahajan et al. 2012). Quantitative assay of L-asparaginase production was determined for the extracellular type II L-asparaginase obtained in the supernatant resulted from centrifugation of the culture broth at $1957 \times g$ and $4{ }^{\circ} \mathrm{C}$ for 20 min (Jain et al. 2012). While the intracellular type I enzyme was assayed in the lysate produced by sonicating the washed and resuspended pellets (in $50 \mathrm{mM}$ Tris $\mathrm{HCl}$ $\mathrm{pH}$ 7.5) in $30 \mathrm{ml}$ lysis buffer (Straight et al. 2007). The resulting lysate was centrifuged for $15 \mathrm{~min}$ at $17,609 \times \mathrm{g}$ and $4{ }^{\circ} \mathrm{C}$ for the removal of unbroken cells and cellular debris (Sakr et al. 2014). The intracellular enzyme activity was then determined in the collected supernatant. L-asparaginase quantitative assessment was carried out using the method described by Mashburn and Wriston (1963). The enzyme acts on L-asparagine substrate contained in the assay to release ammonia. One unit of L-asparaginase activity was defined as the amount of the enzyme that required for the release of $1 \mu$ mole ammonia under the assay condition $\left(37^{\circ} \mathrm{C}, \mathrm{pH} 8.6,1 \mathrm{~h}\right.$ incubation period) (Mahajan et al. 2014).

\section{Identification of the selected test isolate}

The selected isolate of the highest L-asparaginase productivity was characterized by investigation under the microscope, determining its biochemical profile by Vitek ${ }^{\circledR}$ system and its identity was confirmed by sequencing the 16S rRNA gene of the organism chromosomal DNA.

\section{Bioinformatics analysis}

The relatedness of L-asparaginase from Stenotrophomonas maltophilia to those retrieved from NCBI database including those from E. coli and Erwinia chrysanthemi (commercially available as Elspar and Erwinaze, respectively) were inferred by the Maximum Likelihood method based on the JTT matrix-based model (Jones et al. 1992). The molecular evolutionary genetic analyses were done using MEGA X (Kumar et al. 2018). The antigenic sites in Stenotrophomonas maltophilia L-asparaginase relative to those in the commercially available L-asparaginases of E. coli and Erwinia chrysanthemi could be predicted by the software developed using the method of Kolaskar and Tongaonkar (1990) (EMBOSS: antigenic-Bioinformatics web site http://www.bioin formatics.nl/cgi-bin/emboss/antigenic).

\section{Characterization of Stenotrophomonas maltophilia EMCC2297 L-asparaginase}

The enzyme of the test isolate (cell free culture supernatant) was tested for various characters that will determine its application scope. These included stability at different temperatures, optimum temperature and $\mathrm{pH}$ for activity, activity at different concentrations each of sodium chloride, asparagine (substrate) and metal salts. 


\section{Isolate improvement for L-asparaginase production}

Treatment with gamma radiation was used for improving L-asparaginase production by the test isolate. Aliquots (5 ml each) of an overnight growth culture of the test isolate, in a glass tubes were treated at various gamma rays doses (from 0.1 to $5 \mathrm{KGy}$ ) (Hoe et al. 2016). After treatment the L-asparaginase productivity for a number of randomly selected colonies were assessed qualitatively as well as quantitatively (Abdelrazek et al. 2019) and compared to the enzyme productivity of the parent isolate. The variant that gave the maximum enzyme production was subjected for further studies.

\section{Optimization of L-asparaginase production by the selected variant}

L-asparaginase production by the selected variant was tested at different temperatures, initial $\mathrm{pH}$ values, periods of incubation, agitation levels and various components of the used culture media. For each tested parameters the enzyme productivity was measured at the end of incubation period as described by Abdelrazek et al. (2019). While a time course for enzyme production was carried out for determining the incubation period required for maximum L-asparaginase production.

\section{Optimization by Response Surface Methodology}

From a number of experiments carried out one at a time, four parameters affecting $\mathrm{L}$-asparaginase production which included temperature of incubation, designated as (A); initial $\mathrm{pH}$, designated as (B); incubation period, designated as $(C)$ and rate of agitation designated as (D) were subjected to analysis by Response Surface Methodology experimental design (Box-Behnken design). Three levels of each test parameter were applied to describe $\mathrm{L}$-asparaginase production. The mean level, designated as (0) which represents the one of the maximum L-asparaginase production, while the other 2 levels represent the one above, designated as $(+1)$ and the one below, designated as $(-1)$ this mean level. The range of variables studied is represented as Additional file 1: Table S7. The analyses procedures were carried out as described by Abdelrazek et al. (2019) using the values listed in Additional file 1: Table S7.

\section{Optimization by adjusting the components of the used culture media}

The effect of various sources of carbon and nitrogen as well as metal ions was tested for studying their effect on enzyme production by the test variant. Dextrose, yeast extract and sulphate salt of magnesium as a carbon, nitrogen and metal ion sources, respectively were examined at various concentrations.
Statistical data analyses and graphical representations The mean values and standard deviation (presented as error bars) from triplicate conducted experiments were determined. Both one way ANOVA and Dunnett's Multiple Comparison Test were applied using Graph Pad Prism Version 5.0 software for data analyses.

\section{Results}

\section{Isolation and identification of a Stenotrophomonas} maltophilia isolate

A soil isolate with potential production of $\mathrm{L}$-asparaginase could be scored as mentioned in "Materials and methods" among 722 recovered isolates. Both biochemical reaction using Vitek ${ }^{\circledR}$ system and 16S rRNA sequencing revealed the identity of this organism as Stenotrophomonas maltophilia. This isolate was deposited at Microbiological Resources Centre (Cairo Mircen) under the code EMCC2297 and its 16S rRNA sequence was submitted and deposited in NCBI database under the Accession code MG665996. The test isolate used in the present study could produce L-asparaginase extracellularly (Type II L-asparaginase) at a level 4.7 folds more than its intracellular level.

\section{Phylogeny and antigenicity for L-asparaginase of Stenotrophomonas maltophilia}

Figure 1 shows the tree describing the molecular phylogeny of L-asparaginase produced by Stenotrophomonas maltophilia test isolate. This tree was produced upon aligning amino acids sequence of Stenotrophomonas maltophilia L-asparaginase against the corresponding sequences deposited in NCBI database of similarities not less than 58\%. While, Fig. 2 shows the amino acid alignment of the target query L-asparaginase against those of the two commercially available E. coli and Erwinia chrysanthemi L-asparaginases (Elspar and Erwinaze, respectively). For comparison of plant type L-asparaginase and bacterial species ones, a molecular phylogenetic tree for Stenotrophomonas maltophilia L-asparaginase and those of the two reference bacterial strains, E. coli and Erwinia chrysanthemi, as well as the plant type of Medicago truncatula was constructed (Additional file 1: Fig. S1). Pairwise distances among bacterial L-asparaginases illustrated in Fig. 1 are shown in Additional file 1: Table S3 while the corresponding distances among bacterial species L-asparaginases and those of plant type ones in Additional file 1: Fig. S2 are illustrated in Additional file 1: Table S3.

Analysis by EMBOSS antigenic explorer ${ }^{\circledR}$ (Rice et al. 2000) revealed 18,16 and 14 antigenic regions, for $E$. coli, Erwinia chrysanthemi and Stenotrophomonas maltophilia $\mathrm{L}$-asparaginases, respectively. The positions 


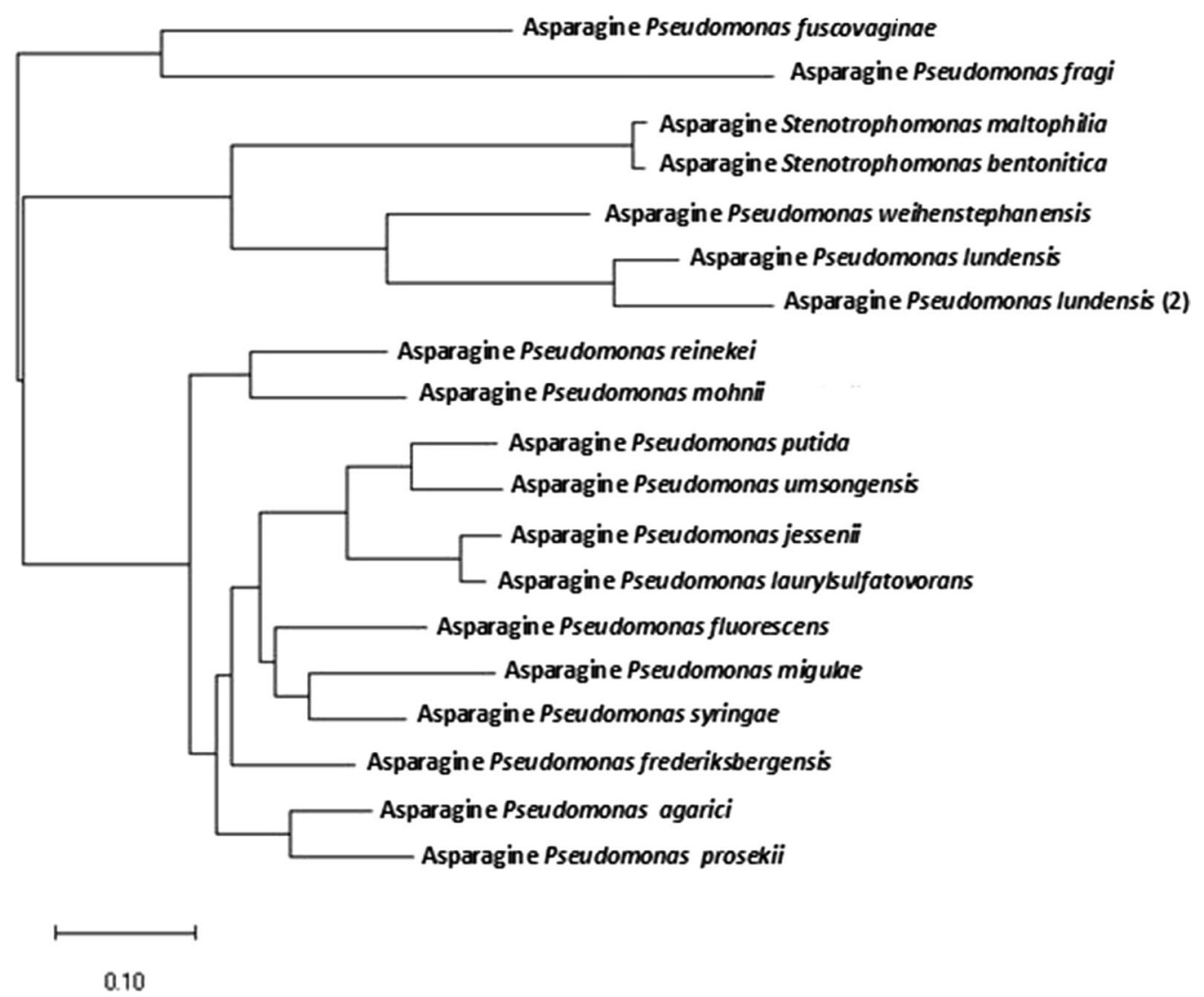

Fig. 1 Phylogenetic analysis of L-asparaginase produced by Stenotrophomonas maltophilia as determined by Maximum Likelihood method. Non redundant amino acid sequences of L-asparaginases retrieved from NCBI databases with similarities more than $56 \%$ were aligned against the query sequence (L-asparaginase of Stenotrophomonas maltophilia) and used for the tree construction. Additional file 1: Table S1 shows query coverage, E value, percent identity and accession numbers of amino acid sequences of $\mathrm{L}$-asparaginases for the tested bacterial species as revealed by NCBI databases

of these antigenic regions together with their amino acid sequences are shown in Table 1.

\section{Characterization of Stenotrophomonas maltophilia EMCC2297 L-asparaginase}

Thermal stability study showed that L-asparaginase of the test isolate could tolerate temperature treatment up to $50{ }^{\circ} \mathrm{C}$ for $30 \mathrm{~min}$ treatment period without appreciable reduction in its activity. The maximum activity was attained at $37^{\circ} \mathrm{C}, \mathrm{pH} 8.6$ and $40 \mathrm{mM}$ asparagine concentration and there was an increase in the activity by about $50 \%$ at half molar sodium chloride concentration. The results of the present study for Stenotrophomonas maltophilia L-asparaginase showed that the chloride salts of either nickel or cobalt and the sulphate salts of either copper or ferrous were not required for the enzyme activity (Fig. 3).

\section{Stenotrophomonas maltophilia EMCC2297 improvement} for L-asparaginase production

Random mutation by treatment with gamma rays (5 KGy) could successfully improve the test isolate for $\mathrm{L}$-asparaginase production. The selected variant showed 1.6 folds increase in L-asparaginase productivity compared to the wild type parent strain.

\section{Production optimization of L-asparaginase} by Stenotrophomonas maltophilia variant (a) Optimization through studying environmental conditions and statistical design of experiments by Response Surface Methodology (RSM)

The preliminary studies (Fig. 4) revealed that; the used Stenotrophomonas maltophilia variant could maximally produce $\mathrm{L}$-asparaginase at $37^{\circ} \mathrm{C}$. Regarding the effect of $\mathrm{pH}$ on L-asparaginase production by the test variant, it was found that maximum enzyme productivity occurred at initial $\mathrm{pH}$ 7. Maximum L-asparaginase production occurred at $24 \mathrm{~h}$ of incubation. Regarding agitation, low 


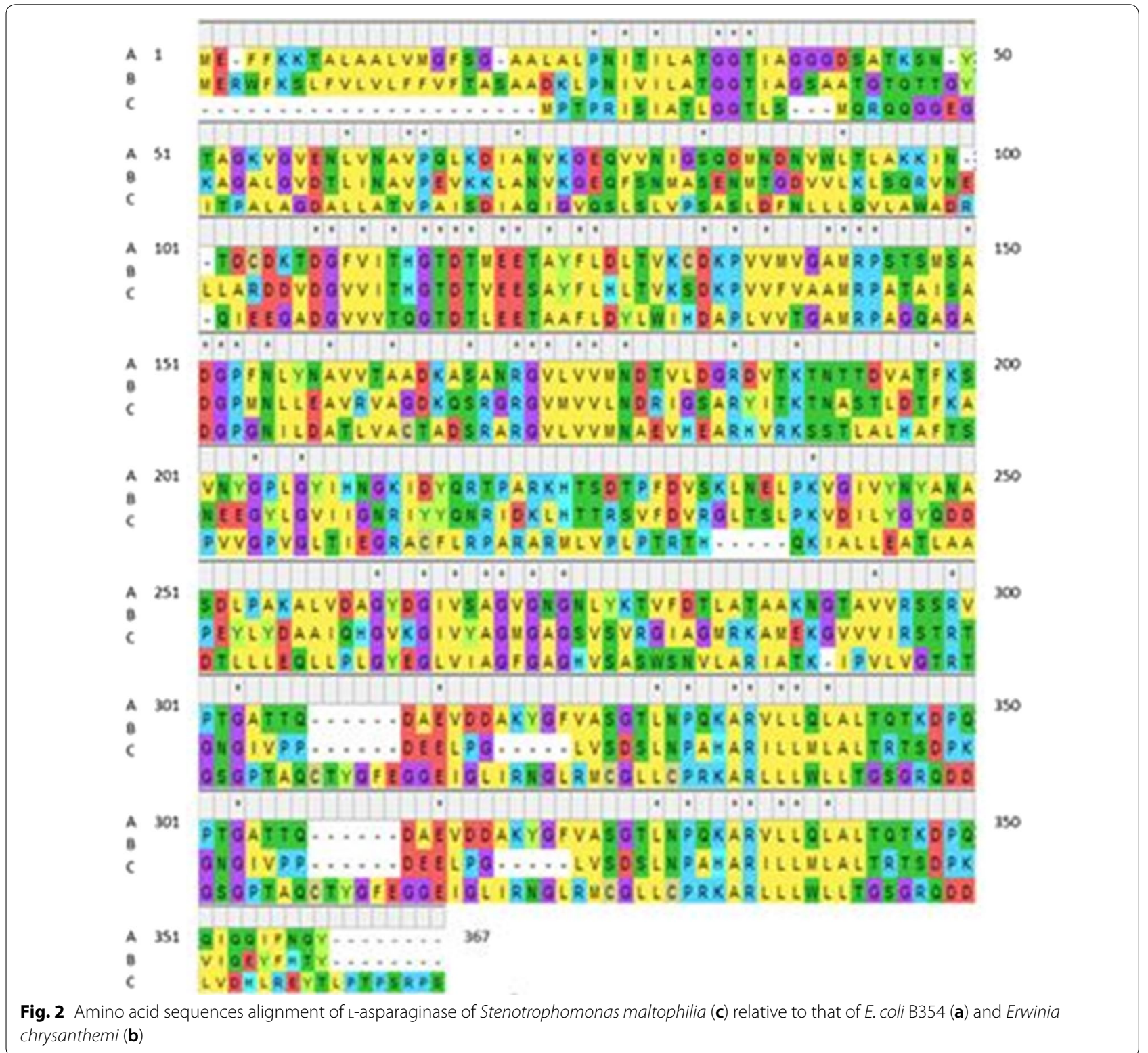

rates did not support high enzyme production, while increasing agitation rate was accompanied by gradual increase in L-asparaginase production till maximum level that was achieved at $180 \mathrm{rpm}$, followed by a decline.

The four previous tested environmental conditions (temperature of incubation, initially used $\mathrm{pH}$, incubation period and the rate of agitation) were subjected to RSM model for designing a number of experiments that could optimally increase L-asparaginase production. Table 2 shows the model results (observed, predicted and residual values). The square root values of L-asparaginase productivity in relation to the tested parameters (variables) could be described by polynomial equation of second order as follows:

$$
\begin{aligned}
\text { Sqrt }(\mathrm{L}-\text { asparaginase activity })= & +2.72+0.018 * \mathrm{~A}-2.110 \mathrm{E}-003 * \mathrm{~B}-0.070 * \mathrm{C} \\
& -7.744 \mathrm{E}-003 * \mathrm{D}-0.058 * \mathrm{~A} * \mathrm{~B}-0.024 * \mathrm{~A} * \mathrm{C} \\
& +0.085 * \mathrm{~A} * \mathrm{D}+0.017 * \mathrm{~B} * \mathrm{C}+0.031 * \mathrm{~B} * \mathrm{D} \\
& -0.032 * \mathrm{C} * \mathrm{D}-0.92 * \mathrm{~A}^{2}-0.88 * \mathrm{~B}^{2}+0.030 * \mathrm{C}^{2}-0.064 * \mathrm{D}^{2}
\end{aligned}
$$




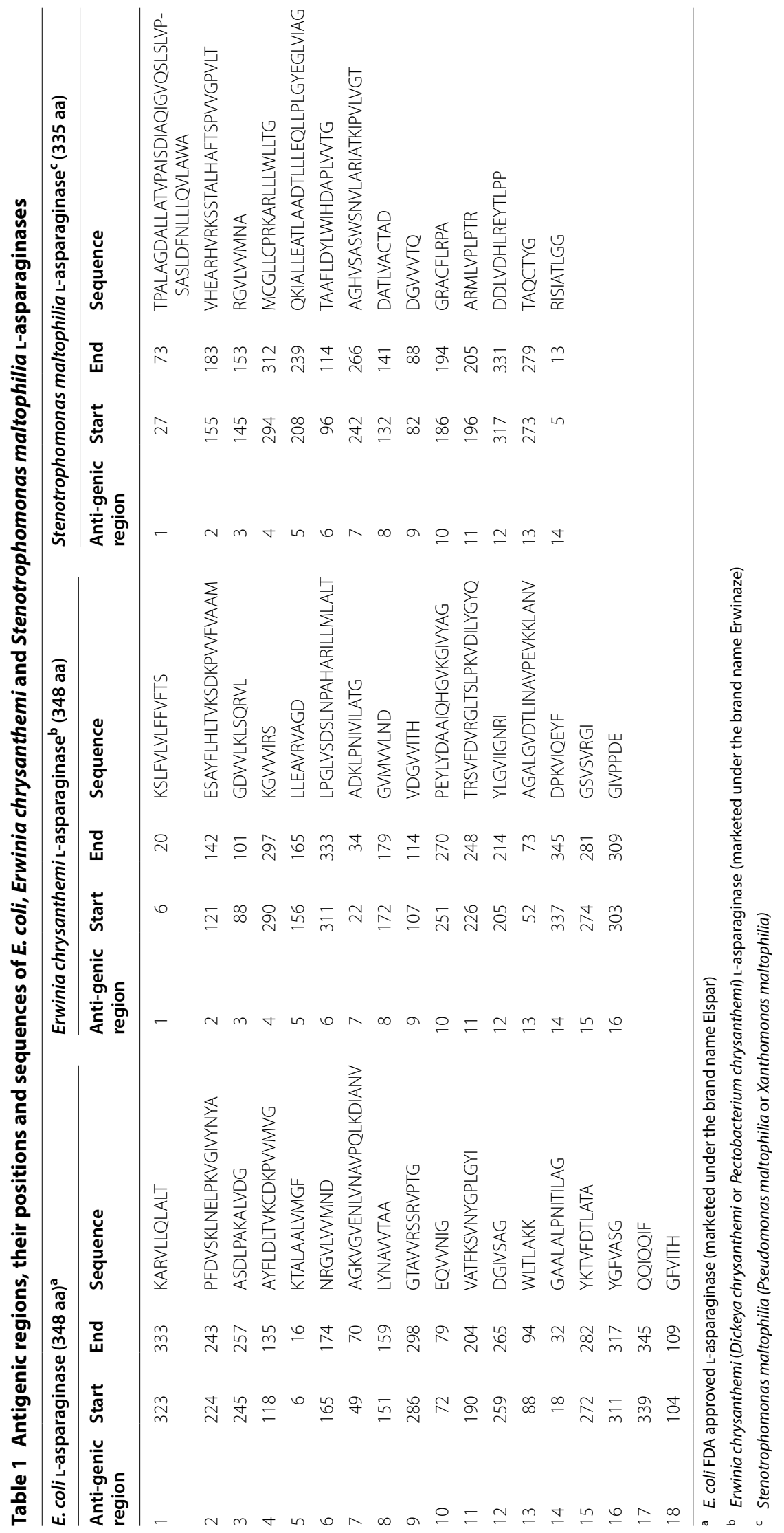




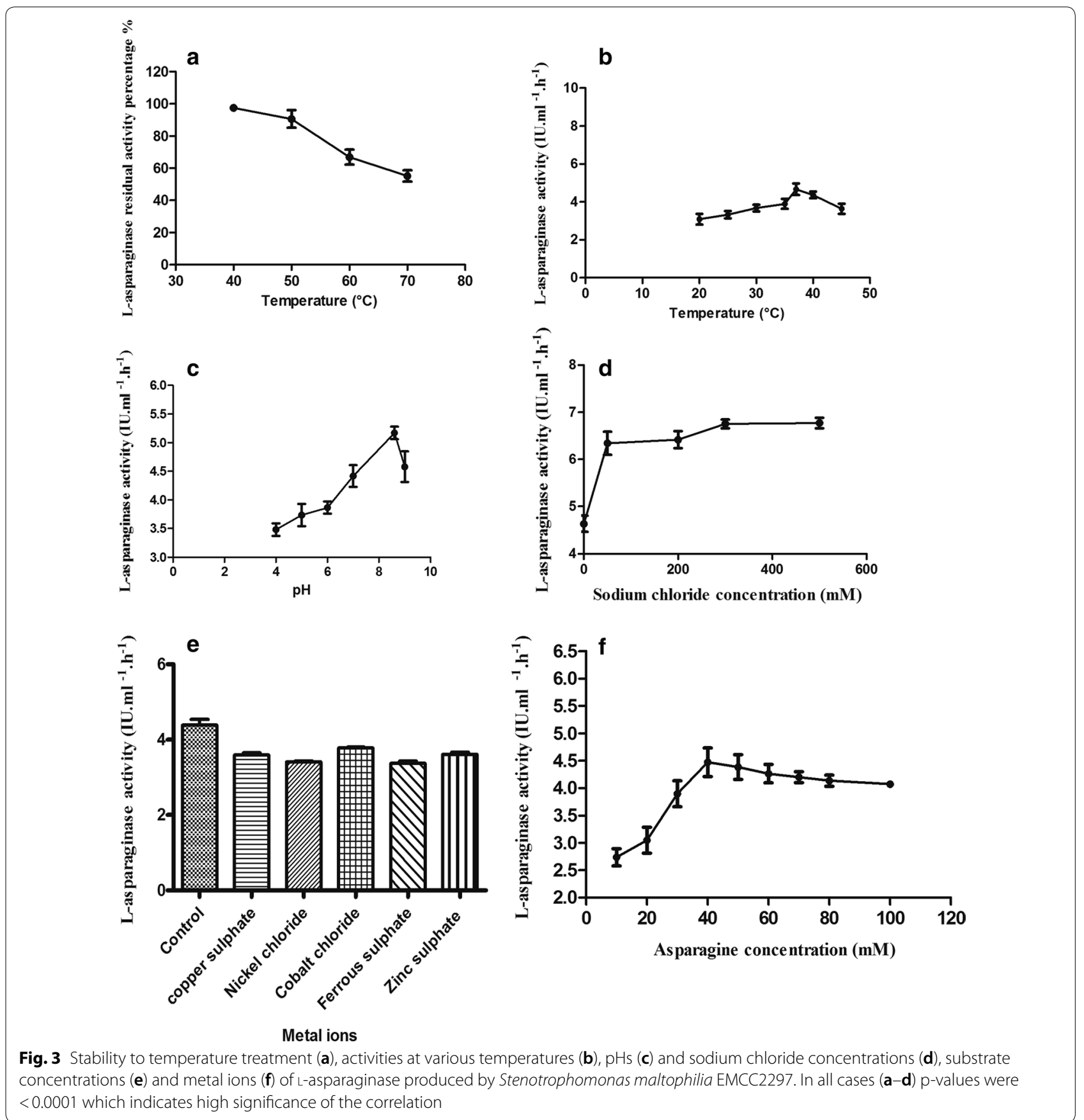

The letters A, B, C and D refer to temperature of incubation, initially used $\mathrm{pH}$, incubation period and rate of agitation, respectively while the L-asparaginase activity was determined in terms of square root values.

ANOVA of the resultant quadratic design was shown as Additional file 1: Table S3 online. For the Model obtained F-value (15.47), a $p$-value lower than 0.0001 . The $R^{2}$ was computed to be 0.9475 , The "Adjusted R-Squared" of 0.8863 , "Predicted R-Squared" of 0.7028. "Adequate precision" was 13.564. The coefficient of variation value was $1.23 \%$. The above mentioned criteria and considerations are used as indicators for the regression model to be valid and adequate. In our study the parameters that confirmed to be significance for $\mathrm{L}$-asparaginase production by the test variant are mentioned in Table 3. 

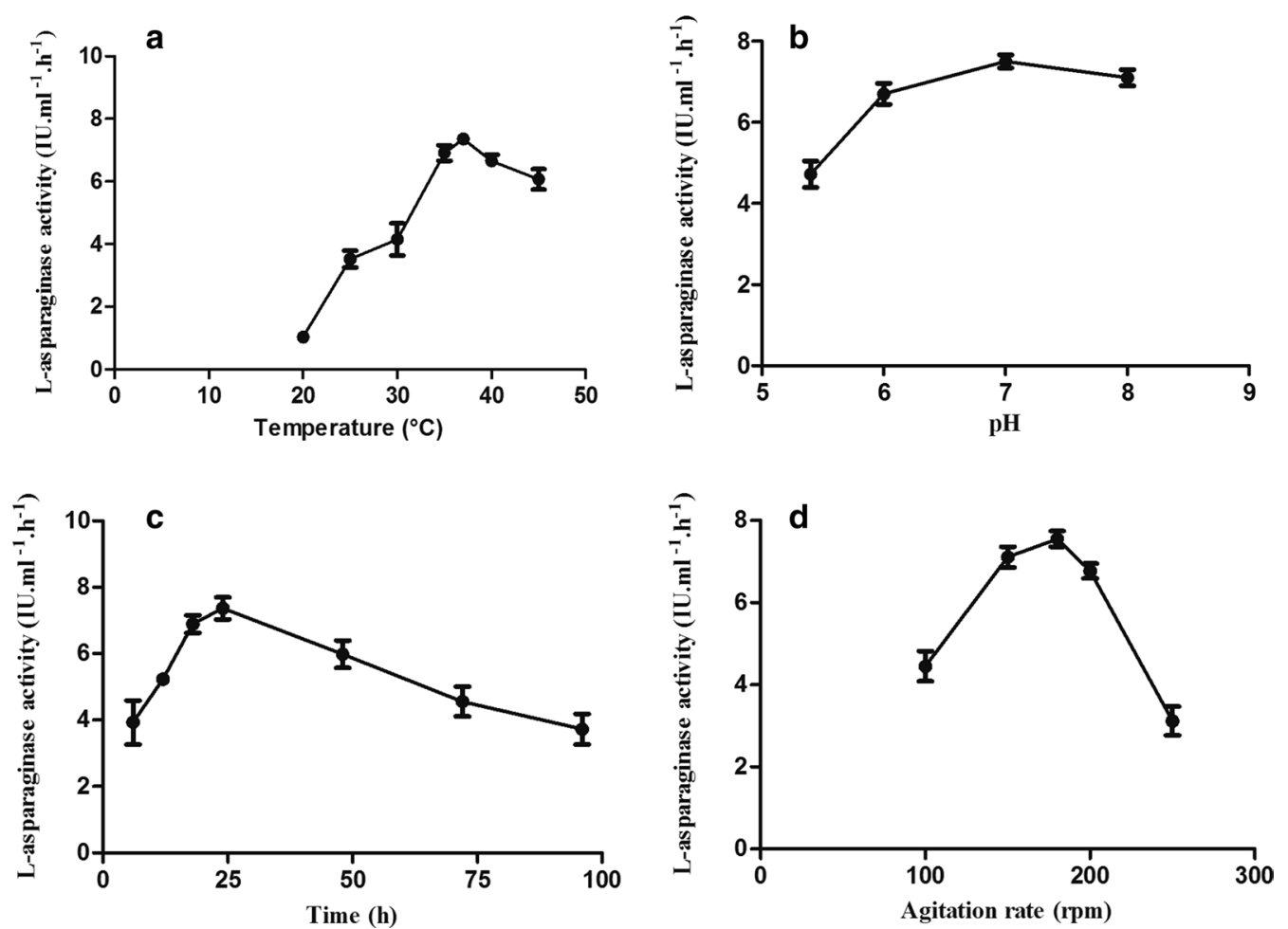

Fig. 4 L-asparaginase production by Stenotrophomonas maltophilia EMCC2297 variant at different temperatures of incubation (a), initial pH values (b), incubation periods (c) and rates of agitation (d)

\section{Bidirectional cross interactions of the tested} parameters for L-asparaginase production by the used Stenotrophomonas maltophilia EMCC2297 variant

The bidirectional cross interactions were expressed as 3D and $2 \mathrm{D}$ for response surface and contour plots, respectively (Fig. 5). These plots were constructed from the data obtained from the regression equation. The effect of interaction of temperature of incubation with $\mathrm{pH}$ and rate of agitation are shown in Fig. 5a, b. These interactions resulted in predicted values for maximum productivity of L-asparaginase of $7.42 \mathrm{IU} / \mathrm{ml} / \mathrm{h}$ at $\mathrm{pH} 6.87$ and temperature of incubation $37.68{ }^{\circ} \mathrm{C}$ and of $7.43 \mathrm{IU} / \mathrm{ml} / \mathrm{h}$ at the same temperature of incubation $\left(37.68{ }^{\circ} \mathrm{C}\right)$ and rate of agitation $175.47 \mathrm{rpm}$. The effect of interaction of $\mathrm{pH}$ with the rate of agitation and incubation period is shown in Fig. 5c, d.

These interactions resulted in predicted values for maximum productivity of L-asparaginase of $7.43 \mathrm{IU} / \mathrm{ml} / \mathrm{h}$ at $\mathrm{pH} 7$ and $173 \mathrm{rpm}$ and of $7.98 \mathrm{IU} / \mathrm{ml} / \mathrm{h}$ at the same $\mathrm{pH}(7)$ and at an incubation period of $18.0 \mathrm{~h}$. The effect of interaction of incubation period with temperature of incubation and rate of agitation are shown in Fig. 5e, f. These interactions resulted in predicted values for maximum productivity of L-asparaginase of $7.98 \mathrm{IU} / \mathrm{ml} / \mathrm{h}$ at temperature of incubation at $37.5{ }^{\circ} \mathrm{C}$ and incubation period
$18.0 \mathrm{~h}$ and of $7.98 \mathrm{IU} / \mathrm{ml} / \mathrm{h}$ at the same incubation period $(18.0 \mathrm{~h})$ and at $175 \mathrm{rpm}$ rate of agitation. These graphs can lead us to some conclusions regarding the enzyme production; decreasing the $\mathrm{pH}$ of the medium from 7 increases the L-asparaginase productivity. This effect is much more pronounced when the temperature is shifted away from $37^{\circ} \mathrm{C}$, when the agitation increased above 175 or decreasing incubation time. Increasing the rate of agitation increases the production of $\mathrm{L}$-asparaginase, this effect gets much more significant by increasing temperature or decreasing time towards $18 \mathrm{~h}$.

The main goal of Response Surface Methodology application is to determine the process value for each variable to be optimum for maximizing the output of the studied process. In this study application of the model resulted in prediction of maximum production level of L-asparaginase by the used Stenotrophomonas maltophilia variant of $7.95 \mathrm{IU} / \mathrm{ml} / \mathrm{h}$. This maximum enzyme level can be obtained at $38.11{ }^{\circ} \mathrm{C}$ temperature of incubation, $\mathrm{pH}$ of $6.89,19.85 \mathrm{~h}$ incubation period and $179.15 \mathrm{rpm}$ rate of agitation.

\section{(b) By testing the components of the applied culture medium}

By studying the influence of various carbohydrate sources which included maltose, glycerol, fructose, 
Table 2 Optimization of process parameters for L-asparaginase production by Stenotrophomonas maltophilia EMCC2297 variant using Box-Behnken design

\begin{tabular}{|c|c|c|c|c|c|c|c|}
\hline \multirow[t]{2}{*}{ Experiment } & \multirow[t]{2}{*}{$\operatorname{Temp}\left({ }^{\circ} \mathrm{C}\right)$} & \multirow[t]{2}{*}{$\mathrm{pH}$} & \multirow[t]{2}{*}{ Time (h) } & \multirow[t]{2}{*}{ Agitation (rpm) } & \multicolumn{2}{|c|}{$\begin{array}{l}\text { Square root of L-asparaginase activity (IU/ } \\
\mathrm{ml} / \mathrm{h} \text { ) }\end{array}$} & \multirow[t]{2}{*}{ Residual value } \\
\hline & & & & & Observed value & Predicted value & \\
\hline 1 & 35 & 6 & 33 & 175 & 2.5 & 2.47 & 0.03 \\
\hline 2 & 40 & 6 & 33 & 175 & 2.6 & 2.62 & -0.02 \\
\hline 3 & 35 & 8 & 33 & 175 & 2.62 & 2.58 & 0.04 \\
\hline 4 & 40 & 8 & 33 & 175 & 2.48 & 2.5 & -0.02 \\
\hline 5 & 37.5 & 7 & 18 & 150 & 2.75 & 2.74 & 0.01 \\
\hline 6 & 37.5 & 7 & 48 & 150 & 2.67 & 2.66 & 0.01 \\
\hline 7 & 37.5 & 7 & 18 & 200 & 2.79 & 2.78 & 0.01 \\
\hline 8 & 37.5 & 7 & 48 & 200 & 2.58 & 2.58 & 0 \\
\hline 9 & 35 & 7 & 33 & 150 & 2.62 & 2.64 & -0.02 \\
\hline 10 & 40 & 7 & 33 & 150 & 2.55 & 2.51 & 0.04 \\
\hline 11 & 35 & 7 & 33 & 200 & 2.44 & 2.46 & -0.02 \\
\hline 12 & 40 & 7 & 33 & 200 & 2.7 & 2.66 & 0.04 \\
\hline 13 & 37.5 & 6 & 18 & 175 & 2.75 & 2.76 & -0.01 \\
\hline 14 & 37.5 & 8 & 18 & 175 & 2.71 & 2.72 & -0.01 \\
\hline 15 & 37.5 & 6 & 48 & 175 & 2.6 & 2.58 & 0.02 \\
\hline 16 & 37.5 & 8 & 48 & 175 & 2.64 & 2.61 & 0.03 \\
\hline 17 & 35 & 7 & 18 & 175 & 2.69 & 2.69 & 0 \\
\hline 18 & 40 & 7 & 18 & 175 & 2.77 & 2.77 & 0 \\
\hline 19 & 35 & 7 & 48 & 175 & 2.57 & 2.6 & -0.03 \\
\hline 20 & 40 & 7 & 48 & 175 & 2.56 & 2.59 & -0.03 \\
\hline 21 & 37.5 & 6 & 33 & 150 & 2.6 & 2.61 & -0.01 \\
\hline 22 & 37.5 & 8 & 33 & 150 & 2.52 & 2.55 & -0.03 \\
\hline 23 & 37.5 & 6 & 33 & 200 & 2.53 & 2.54 & -0.01 \\
\hline 24 & 37.5 & 8 & 33 & 200 & 2.58 & 2.59 & -0.01 \\
\hline $25^{\mathrm{a}}$ & 37.5 & 7 & 33 & 175 & 2.71 & 2.72 & -0.01 \\
\hline $26^{\mathrm{a}}$ & 37.5 & 7 & 33 & 175 & 2.73 & 2.72 & 0.01 \\
\hline $27^{\mathrm{a}}$ & 37.5 & 7 & 33 & 175 & 2.74 & 2.72 & 0.02 \\
\hline
\end{tabular}

${ }^{a}$ Refers to the experiments that were carried out in triplicates at the mean value of each tested parameter (temperature of incubation, initial pH, time of incubation, rate of agitation)

Table 3 Summarization of parameters that significantly influence L-asparaginase production by Stenotrophomonas maltophilia EMCC2297 variant arranged in a descending order

\begin{tabular}{ll}
\hline Order & Process parameter factor \\
\hline 1 & Time of incubation \\
2 & Temperature of incubation in square terms \\
3 & Initial pH in square terms \\
4 & Interaction between incubation temperature and agitation rate \\
5 & Square term of agitation rate \\
6 & Interaction between incubation temperature and initial $\mathrm{pH}$
\end{tabular}

starch, dextrose, sucrose, lactose and arabinose, dextrose (at $0.5 \% \mathrm{w} / \mathrm{v}$ ), yeast extract (at $0.1 \% \mathrm{w} / \mathrm{v}$ ), magnesium $(10 \mathrm{mM})$ were the best carbohydrate, nitrogen source, metal ions for maximum production of L-asparaginase, respectively (Fig. 6).

\section{Discussion}

$\mathrm{L}$-asparaginase has received considerable attention as a primary component in the treatment of acute lymphoblastic leukemia (ALL) (Sinha et al. 2013). Also acts as a biosensor to detect the amount of asparagine in leukemia and food industry (Batool et al. 2016). A complete identification of our microorganism was done by biochemical tests and confirmed by the $16 \mathrm{~S}$ rRNA sequencing. The genotypic identification of bacteria is generally more accurate than the traditional identification on the basis of phenotypic characteristics. The $16 \mathrm{~S}$ rRNA sequencing was found to be a phylogenetic tool also useful for bacterial detection and identification, it can better identify poorly described strains (Matsumoto and Sugano 


\section{a}

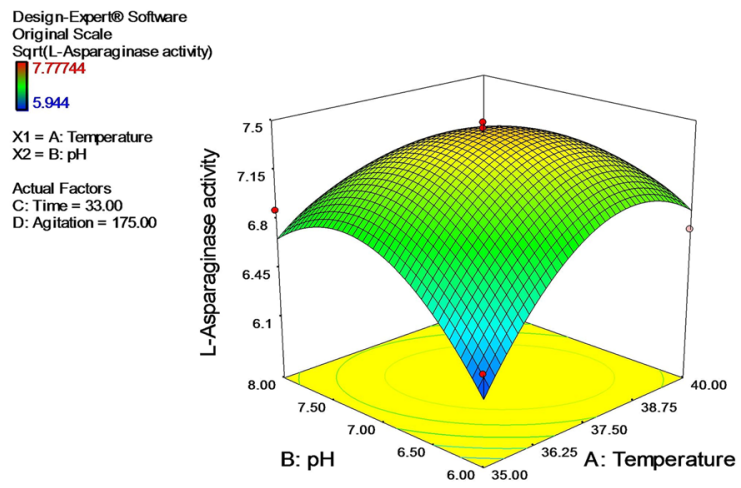

C

Design-Expert Softwar Original Scale

Sqrit(L-Asparaginase activity)

Sqrt(L-Asparag
7.77744

5.944

$\mathrm{X} 1=\mathrm{B}: \mathrm{pH}$ X2 = D: Agitation

Actual Factors A: Temperature $=37.50$ C: Time $=33.00$

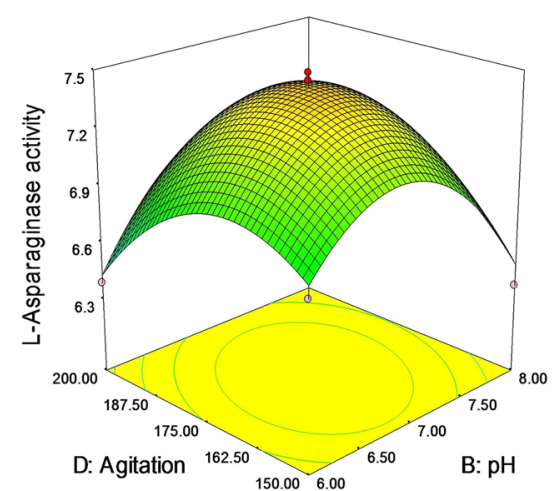

\section{e}

Design-Exper@ Software

Original Scale

Sqrt(L-Asparaginase activity)

$\prod_{5.944}^{7.77744}$

$\mathrm{X} 1=\mathrm{C}:$ Time

$\mathrm{X} 2=\mathrm{A}:$ Temperature

Actual Factors

D: Agitation $=175.00$

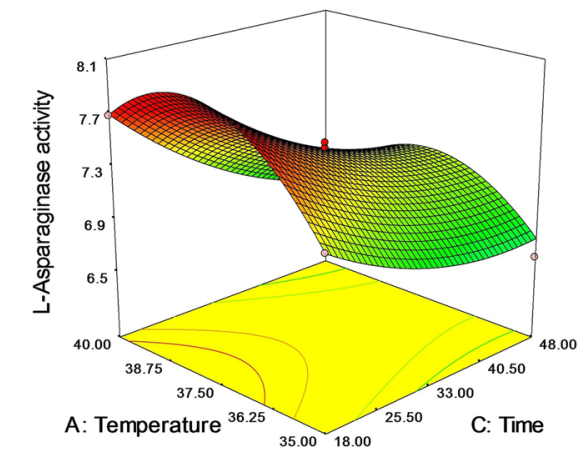

b

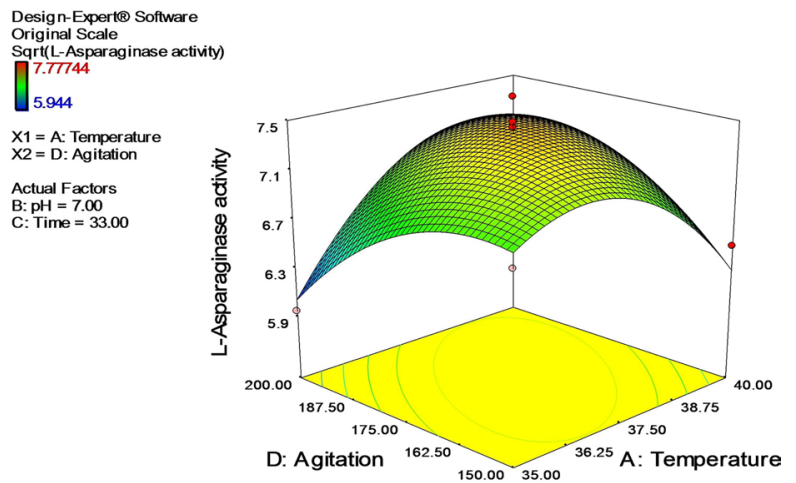

d

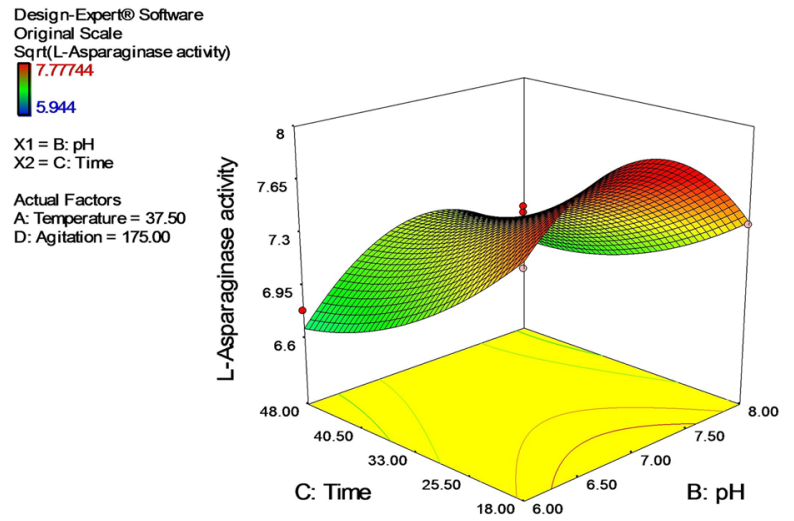

(a)

5.944

$\mathrm{X} 1=\mathrm{B}: \mathrm{pH}$
$\mathrm{X} 2=\mathrm{C}: \mathrm{Tim}$

Actual Factors

$18.00 \quad 6.00$

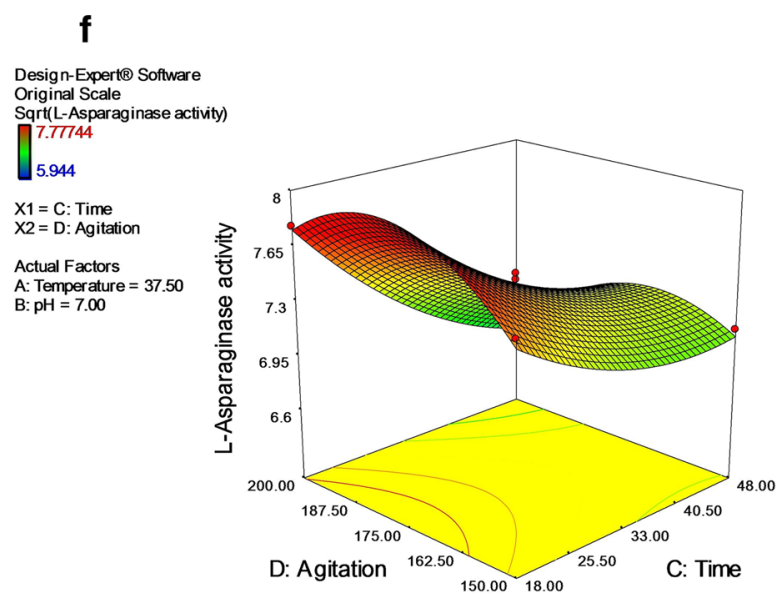

Fig. 5 Graphs showing process parameters optimization for L-asparaginase production by Stenotrophomonas maltophilia EMCC2297 variant as revealed by Response surface methodology analysis. The graphs show the interactions between: a temperature of incubation $\left({ }^{\circ} \mathrm{C}\right)$ and $\mathrm{pH} ; \mathbf{b}$ temperature of incubation $\left({ }^{\circ} \mathrm{C}\right)$ and rate of agitation (rpm); $\mathbf{c ~ p H}$ and rate of agitation (rpm); $\mathbf{d ~ p H}$ and incubation periods (h); e incubation periods (h) and temperature of incubation $\left({ }^{\circ} \mathrm{C}\right)$; and $\mathbf{f}$ incubation periods (h) and rate of agitation (rpm)

2013). Extracellular enzymes have an advantage of being they don't need cell breakage allowing their cost effective purification (Deokar et al. 2010; Joseph and Rajan 2011).
Fortunately, our test isolate that used in the present study could produce L-asparaginase extracellularly (Type II L-asparaginase) at a level $470 \%$ more than its intracellular 

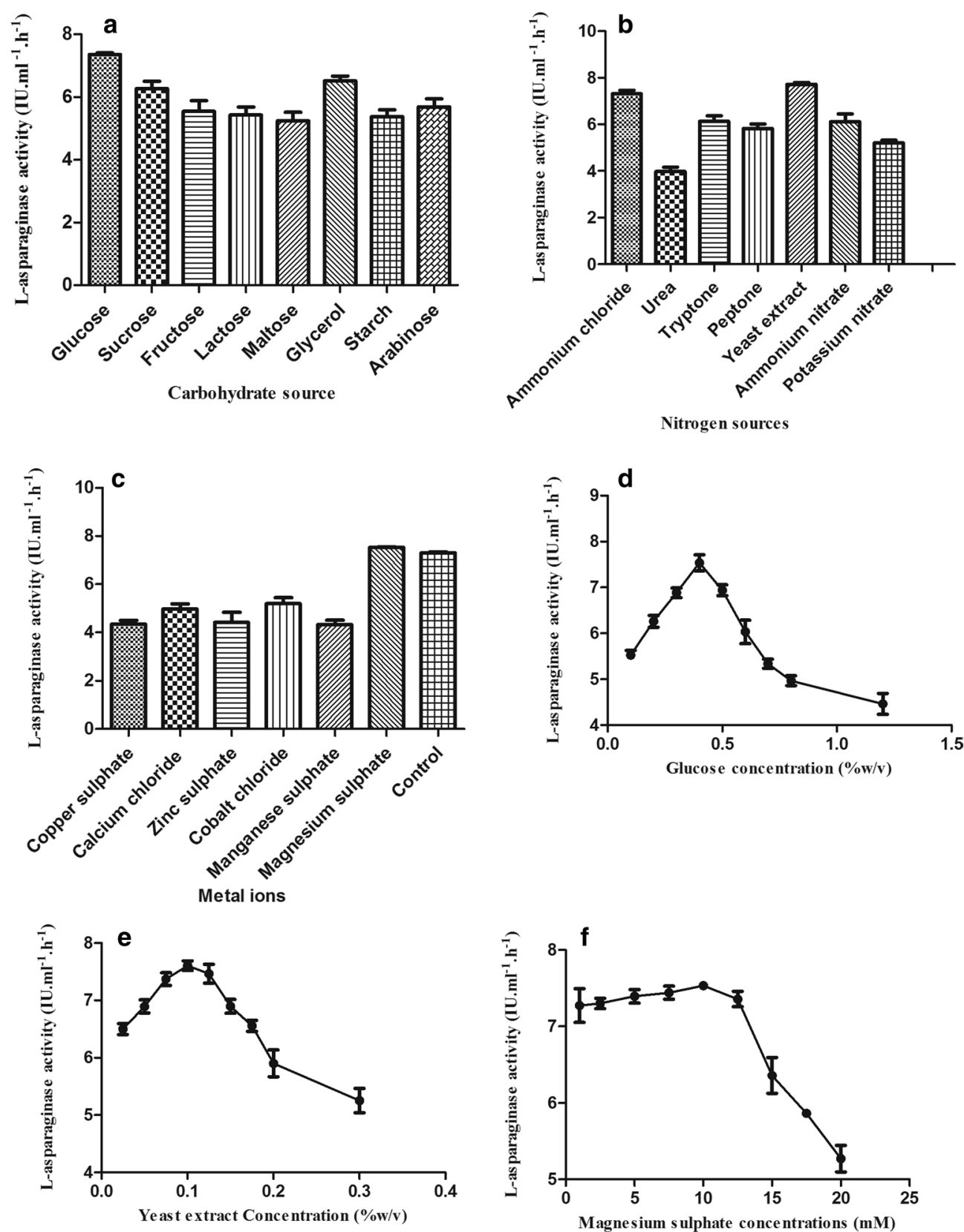

Fig. 6 L-asparaginase production by Stenotrophomonas maltophilia EMCC2297 variant at various sources of a carbohydrate, b nitrogen, c metal salts and various concentrations of $\mathbf{d}$ dextrose, $\mathbf{e}$ yeast extract and $\mathbf{f}$ sulphate salt of magnesium. In all cases (a-f) p-values were $<0.0001$ which indicates high significance of the correlation

level. Bacterial L-asparaginases are defined by their intra or extra cellular localization (Michalska and Jaskolski 2006). Type I (cytosolic) binds to L-asparagine with low affinity, in contrast the extracellular type II (periplasmic) has a strong binding capacity and it has a characteristic oligomeric form. For more than 30 years, type II asparaginases (Campbell and Mashburn 1969), from Escherichia coli and Erwinia chrysanthemi, were used in the treatment of acute lymphoblastic leukemia and some other tumor types (Bodey et al. 1974; Boyse et al. 1967; Roberts et al. 1966; Lay et al. 1975). Thus, the extracellular L-asparaginase of the test isolate was our focus in the present study.

By testing the phylogeny and antigenicity for L-asparaginase of Stenotrophomonas maltophilia, it is obvious that L-asparaginases of Stenotrophomonas species 
(maltophilia and bentonitica) are clustered with two Pseudomonas species (weihenstephanensis and lundensis). This cluster shows different degree of relatedness to clusters and sub-clusters of other Pseudomonas species presented. L-asparaginases of Pseudomonas fragi and Pseudomonas lundensis are distantly related. The relationship between the plant type L-asparaginase and bacterial species ones is an important factor to allow the formation of complete profile for Stenotrophomonas L-asparaginase so a comparison between them was done, the results demonstrated the degree of closeness and relatedness of these enzyme sources. Although these enzyme sources could be seen in different clusters in the tree, the maximum obtained pairwise distance did not exceed 0.7175 which was recorded between Pseudomonas lundensis and Pseudomonas fragi L-asparaginases. Measuring the corresponding distances among bacterial species L-asparaginases and those of plant type ones showed clustering of $E$. coli L-asparaginase with that of Erwinia chrysanthemi with a pairwise distance of 0.750 and considerable relatedness of Stenotrophomonas maltophilia L-asparaginase with each of $E$. coli and E. chrysanthemi, pairwise distances 1.201 and 1.191, respectively. A distant relatedness was observed between the plant type L-asparaginase and those of Stenotrophomonas maltophilia, E. coli and E. chrysanthemi with pairwise distances of 2.233, 2.398 and 2.197, respectively. Analysis of the antigenic epitopes showed that the lowest antigenicity was obtained with Stenotrophomonas maltophilia L-asparaginase followed by that of Erwinia chrysanthemi while that of $E$. coli is the one of the highest number of antigenic regions. Cavanna et al. (1976) stated that depressive and toxic immune mediated effects were demonstrated in L-asparaginase from $E$. coli than from E. carotovora. This result validates the predicted results obtained for L-asparaginases of the three aforementioned strains using EMBOSS antigenic explorer ${ }^{\circledR}$ (Barry et al. 2007). The medical application of L-asparaginases from E. coli and Erwinia is accompanied by partial immune mediated adverse effects of these enzymes. This necessitates the search for other microbial L-asparaginases with minimal immune mediated side effects. Lower antigenic epitopes predicted in L-asparaginase of Stenotrophomonas maltophilia suggests less adverse effects which could support further experimental analysis in vivo animal model for proving the potential introduction of Stenotrophomonas maltophilia $\mathrm{L}$-asparaginase as a therapeutic candidate for medical application.

The aim of this study was not only increasing the production of L-asparaginase but also selecting the L-asparaginase that had industrially needed characteristics. The special characteristics of the enzymes exploited for their industrial applications and commercial interest were tested. The difference between the native and denatured structure of the enzymes limits their applications as the enzymes became fragile in nature. So the enzymes that show stability over $\mathrm{pH}$ ranges and temperature are highly needed in the industrial field. For medical applications thermal stability to temperature higher than this level $\left(50{ }^{\circ} \mathrm{C}\right)$ are mostly not required. These results were the same as that reported by Mahajan et al. (2014) whose results showed that $\mathrm{L}$-asparaginase produced from $B$. licheniformis was more robust than that produced from E. coli (Kumar et al. 2011). However, our results are in agreement with those reported by other authors (Elshafei et al. 2012). Regarding the optimum pH for L-asparaginase activity it was found that the maximum activity occurs at neutral $\mathrm{pH}(7)$ or alkaline $\mathrm{pH}$ (8 and 9). Maximum enzyme activity from Bacillus sp. and Stenotrophomonas maltophilia at neutral $\mathrm{pH}$ was reported by Abdel-Fattah and Olama (2002), El-Mched et al. (2015) and Maysa et al. (2010) while maximum activity at alkaline $\mathrm{pH}$ (8 and 9) for Streptomyces halstedii, Penicillium brevicompactum, B. licheniformis and Streptomyces gulbargensis L-asparaginases was reported by Amena et al. (2010), El-Sabbagh et al. (2013), Elshafei et al. (2012) and Mahajan et al. (2014). The optimum pH for activity obtained in our study was alkaline (8.6) that could be explained in the view of enzyme mechanistic action in terms of the aspartic acid and aspartate balance. At acidic $\mathrm{pH}$ aspartic acid had higher affinity at the enzyme active site, while at the alkaline $\mathrm{pH}$ aspartate had lower affinity to the active site which enabled the binding of asparagine to the enzyme. Also may be due to within acidic $\mathrm{pH}$ inhibition by competition for $\mathrm{L}$-asparaginase is exerted by aspartic acid (El-Sabbagh et al. 2013). It was reported by Persson and Halle (2008) that the biological activity of proteins is essentially dependent on water molecules which attach to the surface and enter into the protein molecules. The water activity in biological system is affected by a various conditions such as extreme $\mathrm{pH}$, temperature or high sodium chloride concentrations. Fortunately in our study the L-asparaginase produced by Stenotrophomonas maltophilia EMCC2297 exhibited increased activity by about $50 \%$ at half molar sodium chloride concentration. This increase in activity could be interpreted by the explanation reported by Han et al. (2014) who stated that salinity can render the structure of the enzyme more flexible in such a way that increases the enzyme activity. The same authors reported that negative charges are associated with halophilic enzymes and the presence of sodium chloride renders these enzymes more flexible with an increase in enzyme activity. The results reported in this study agreed those obtained by many researchers (Dash et al. 2016; Elshafei et al. 2012; Han et al. 2014; Shechtman 2013) who reported that sodium 
chloride increases enzyme activity. Regarding L-asparaginase activity produced by Stenotrophomonas maltophilia test isolate in relation to asparagine concentration, it was found that this relationship obeys the commonly exhibited by various enzymes. That is a proportional increase in enzyme activity occurs by increasing the substrate concentration to a certain level after which either plateau or a decrease in enzyme activity usually happens. Similar results were stated by El-Mched et al. (2015) and the absence of the increase of enzyme activity after certain substrate concentration may be due to the saturation of the enzyme catalytic active site. The results of the present study for Stenotrophomonas maltophilia EMCC2297 L-asparaginase and as reported by Abdelrazek et al. (2019) the chloride salts of either nickel or cobalt and the sulphate salts of either copper or ferrous were not required for L-asparaginase activity. Contrary to the results reported by ${ }^{28}$, the sulphate salt of zinc did not increase the L-asparaginase activity produced by the test isolate. Existence of metal ions reasonably activate the enzyme allowing its suitability for industrial application (Badoei-Dalfard 2016). Fortunately, the maximum activity for L-asparaginase of Stenotrophomonas maltophilia EMCC2297 was obtained at body temperature $\left(37{ }^{\circ} \mathrm{C}\right)$ that can be important for its medical use to assure complete elimination of asparagine from cancer patient.

Strain improvement is an important part of development of microbial product. Arising of strains with high productivity can reduce costs. In the present study mutagenesis was conducted by gamma rays (physical mutagen). Gamma rays is the highest ionizing radiation as well as the most energetic, it causes mutation through breakage of single and double stranded DNA resulting structural changes or oxidation (Huma et al. 2012). Gamma irradiation was reported by many authors (Diep et al. 2017; Hoe et al. 2016; Huma et al. 2012; Hyster and Ward 2016) as an efficient physical mutagen for improving the enzyme production by different microbial strain.

Optimization of production conditions as well as production media components can help in increasing the enzyme production to many folds. So optimization through studying environmental conditions and statistical design of experiments by Response Surface Methodology (RSM) was performed, (RSM) is a statistical program applying mathematical calculations for developing a correlation between a target response and number of variables. The incubation temperature is an important environmental factor for L-asparaginase production by microorganisms, as it regulates the microbial growth and consequently the enzyme production (El-Hefnawy et al. 2015). In our study the maximum production was obtained at $37{ }^{\circ} \mathrm{C}$ either higher or lower temperature showed a decrease in enzyme production as a result of slowing down the microorganisms' metabolic activity (ElHefnawy et al. 2015). Many researchers reported similar results, where maximum productivity of L-asparaginase was obtained at $37{ }^{\circ} \mathrm{C}$ (Bahrani 2016; El-Hefnawy et al. 2015). While others recorded $39{ }^{\circ} \mathrm{C}$ as optimum temperature (Prakasham et al. 2007) or $30^{\circ} \mathrm{C}$ (Jayaramu et al. 2010). The growth of Stenotrophomonas maltophilia at different $\mathrm{pHs}$ revealed that higher or lower initial $\mathrm{pH}$ value than the optimum showed decline in enzyme productivity as it may adversely affect the enzyme production or its activity or both. This agreed with several studies (Bahrani 2016; Kavitha and Vijayalakshmi 2010). However, other optimum $\mathrm{pH}$ values $(6.5,7.5,6)$ for L-asparaginase production were reported by Jayaramu et al. (2010), Pradhan et al. (2013) and Prakasham et al. (2007). The incubation time required for maximum product formation differs according to the microbial strain applied (Maysa et al. 2010; Pradhan et al. 2013). On the other hand, studying the effect of the incubation showed steep wise decrease in enzyme productivity thereafter the optimum time.

The decrease in enzyme productivity after its maximum production level mostly attributed to the enzyme degradation by proteolytic enzyme of the producing organism or production of inhibitors upon depletion of the culture media components. Enzyme formation and production at short incubation periods is preferable for commercial enzyme production as its cost effectiveness and because of the decomposition liability of the produced enzyme is minimized (El-Hefnawy et al. 2015). Various incubation periods were recorded for maximal $\mathrm{L}$-asparaginase production by different microorganisms, $48 \mathrm{~h}$ for Emericella nidulans and Stenotrophomonas maltophilia (Jayaramu et al. 2010; Kavitha and Vijayalakshmi 2010) and $72 \mathrm{~h}$ for Streptomyces tendae and Penicillium oxalicum (ElHefnawy et al. 2015; Kavitha and Vijayalakshmi 2010) and $120 \mathrm{~h}$ for Fusarium spp. (Murali 2011). Regarding the agitation rate, the reason for this result is that agitation could affect the physiological status of the microorganism and consequently its production capability for certain enzyme or metabolite. Although increased agitation could increase nutrition and oxygen availability (Sooch and Kauldhar 2013) and increase nutrient absorption by the microorganisms as well (Pansuriya and Singhal 2011), it might decrease the product formation which could be attributed to the shear stress exerted on the bacterial cells especially at higher agitation rates (Sooch and Kauldhar 2013). Other published researches reported higher production at $220 \mathrm{rpm}$ (Bahrani 2016) and $150 \mathrm{rpm}$ (Pradhan et al. 2013).

After applying the RSM to the four tested parameters, the model showed large model F-value which could occur at a low chance $(0.01 \%)$ and this is attributed to noise. 
A very low probability value $(\mathrm{P}$ model $>\mathrm{F})=0.0001$ of Fisher's F-test gives an evidence that the model is of high significance. The model coefficient regression $\left(R^{2}\right)$ was calculated to indicate the model fitness, its value indicating that the design could clarify the variability by $94.75 \%$. Different statistical criteria have to be checked for validation of the applied model. For example a determination coefficient of high value refers to that the model cannot explain the total variation by a percentage not exceeding $5.25 \%$. The lack of fit F-value of 6.97 and P-value of 0.1319 indicate that lack of fit is non-significant as compared to the pure error as it contrasts the residual error with the "pure error" from replicated design points and that model exhibit excellent fit. The value of the "Adjusted R-Squared" refers that the model can clarify the variability by $88.6 \%$ if the sample was a group of the parameters other than the studied ones, its value is always less than the $\left(\mathrm{R}^{2}\right)$ (Frost 2013). The "Predicted R-Squared" is in considerable compliance (a difference not more than the recommended 0.3 value with the "Adjusted R-Squared") (Frost 2013). This means that the model is of high prediction ability and could explain $70 \%$ of observations in addition to the fed in data that can be successfully anticipated by the model (Frost 2013). "Adequate precision" is expressed in terms of signal to noise ratio. The cut off value of signal to noise ratio for the model is 4 and values greater than this value indicates sufficient and satisfactory signal to noise ratio. Therefore the design space can be navigated by the applied model. The overall consistency of measure determines the model reliability. It is measured by the coefficient of variation which is equal to the standard deviation to the mean ratio. The reliability and precision of the model are attained at lower $\mathrm{CV}$ values, its value implies high reliability and excellent precision (Shechtman 2013). For the CV to be significant F-value magnitude should be large and P-value magnitude should be small (Adinarayana and Ellaiah 2002).

Although dextrose catabolic regression its incorporation could enhance the enzymes/metabolites production by various microorganisms. In the present study dextrose proved to have a positive effect on $\mathrm{L}$-asparaginase biosynthesis by the test organism as it increased the production level of this enzyme. Other authors also reported that dextrose increases the production of L-asparaginase as in case of Aeromonas sp., Aspergillus terreus (Amena et al. 2010; Doriya and Kumar 2016; El-Hefnawy et al. 2015; Gurunathan and Sahadevan 2011; Varalakshmi and Raju 2013). However, other carbohydrate sources were reported for their enhancing effect on L-asparaginase biosynthesis as in case of sucrose and sorbitol for Streptomyces tendae (Kavitha and Vijayalakshmi 2010) and lactose in case of E. coli (Bahrani 2016). Stimulation of the production occurred at low glucose concentrations while inhibition happened at high concentrations which may be due to the catabolic repression effect of glucose. The same results were reported by other workers (ElHefnawy et al. 2015; Gurunathan and Sahadevan 2011). Enzymes productions are highly dependent on the used sources of nitrogen, since these sources affect nucleic acid production and cell wall and protein biosynthesis. In our study yeast extract proved to be the best nitrogen source for $\mathrm{L}$-asparaginase production and this is in agreement with that reported by many researchers (Bahrani 2016; El-Hefnawy et al. 2015; Kavitha and Vijayalakshmi 2010) while ammonium sulphate was the best in others (Varalakshmi and Raju 2013). The maximum production was occurred at $0.1 \%$ yeast extract concentration and it was $0.5 \%$ and $2 \%$ in different studies (Amena et al. 2010; El-Hefnawy et al. 2015; Kavitha and Vijayalakshmi 2010). The increase in $\mathrm{L}$-asparaginase production by magnesium, also recorded in Megavarnam and Janakiraman (2015) and Varalakshmi and Raju (2013). In our study, the maximum $\mathrm{L}$-asparaginase production was obtained at $10 \mathrm{mM}$ magnesium sulphate followed by a remarkable decrease in production of the enzyme by increasing the concentration.

In conclusion, the recovered Stenotrophomonas maltophilia EMCC2297 soil isolate produces L-asparaginase with promising characteristics that can support further work and investigations for its introduction as a candidate for medical and pharmaceutical applications, as it showed lower predicted antigenicity compared to the commercially available used enzymes (Elspar and Erwinaze).

From the present study we can conclude that soil represents an inestimable source of useful microorganisms, among which L-asparaginase producing bacteria. $\mathrm{L}$-asparaginase has a crucial medical application as anticancer agent. The soil recovered isolate, Stenotrophomonas maltophilia, proved to be a promising source for L-asparaginase that can be used medically as it showed lower predicted antigenicity as compared to the commercial available ones (Elspar and Erwinaze). Production conditions for maximum L-asparaginase production were determined in this study and could be applied for commercial exploitation.

\section{Supplementary information}

Supplementary information accompanies this paper at https://doi. org/10.1186/s13568-020-01005-7.

Additional file 1: Table S1. Query coverage, E value, percent identity and accession numbers of amino acid sequences of L-asparaginases for the tested bacterial species as revealed by NCBI databases. Table S2. Pairwise distances among L-asparaginases of bacterial species presented in the phylogenetic tree shown in Fig. 1. Table S3. Pairwise distances among bacterial L-asparaginases of Stenotrophomonas maltophilia, E. 
coli and Erwinia chrysanthemi and the plant L-asparaginase of Medicago truncatula presented in the phylogenetic tree shown in Fig. S1. Table S4. ANOVA of the quadratic model for the process parameters optimization of L-asparaginase productivity by Stenotrophomonas maltophilia EMCC2297 mutant using Box-Behnken central composite design. Table S5. Levels of reaction conditions of process parameters as independent variables studied in RSM experimental design for optimization of L-asparaginase production by the selected test mutant. Table S6. Experiments that were deduced by the RSM experimental design and tested for L-asparaginase production by the test mutant. Fig. S1. Molecular Phylogenetic analysis by Maximum Likelihood method of Stenotrophomonas maltophilia L-asparaginase when blasted against amino acid sequences of the FDA approved L-asparaginases of E. coli and Erwinia chrysanthemi and the plant type L-asparaginase of Medicago truncatula.

\section{Acknowledgements}

The authors would like to thank Dr. Amal Emad and Dr. Nouran Elleboudy for their professional support in genetic based identification and model based optimization, respectively.

\section{Authors' contributions}

The authors contributed to the work done in the manuscript as follows: All authors participated in the design, interpretation of the studies and analysis of the data and review of the manuscript; NAA conducted the laboratory experiments, presented the data in tables and graphs and prepared the preliminary version of the manuscript, WFE revised the experimental design, guided the data analyses and interpretation and manuscript revision, MMR guided the laboratory experiments, helped in the preparation of the first version of the manuscript and analysis of the experimental data, MMA suggested the research area, determined the study topic, bioinformatics analysis, data interpretation and final revision of the manuscript. All authors read and approved the final manuscript.

\section{Funding}

Not applicable.

\section{Availability of data and materials}

Please contact author for data request.

\section{Ethics approval and consent to participate}

This article does not contain any studies with human participants or animals performed by any of the authors.

\section{Consent for publication}

Not applicable.

\section{Competing interests}

The authors declare that they have no competing interests.

\section{Author details}

${ }^{1}$ Department of Microbiology and Immunology, Faculty of Pharmaceutical Sciences and Pharmaceutical Industries, Future University in Egypt, Cairo, Egypt. ${ }^{2}$ Department of Microbiology and Immunology, School of Pharmacy \& Pharmaceutical Industries, Badr University in Cairo (BUC), Entertainment Area, Badr City, Cairo 11829, Egypt. ${ }^{3}$ Department of Microbiology and Immunology, Faculty of Pharmacy, Ain Shams University, African Union Organization St., Abbassia, Cairo 11566, Egypt.

Received: 4 March 2020 Accepted: 7 April 2020 Published online: 15 April 2020

\section{References}

Abdel-Fattah YR, Olama ZA (2002) L-asparaginase production by Pseudomonas aeruginosa in solid-state culture: evaluation and optimization of culture conditions using factorial designs. Process Biochem 38(1):115-122

Abdelrazek NA, Elkhatib WF, Raafat MM, Aboulwafa MM (2019) Experimental and bioinformatics study for production of $\mathrm{L}$-asparaginase from Bacillus licheniformis: a promising enzyme for medical application. AMB Express 9(1):39

Adinarayana K, Ellaiah P (2002) Response surface optimization of the critical medium components for the production of alkaline protease by a newly isolated Bacillus sp. J Pharm Pharm Sci 5(3):272-278

Amena S, Vishalakshi N, Prabhakar M, Dayanand A, Lingappa K (2010) Production, purification and characterization of L-asparaginase from Streptomyces gulbargensis. Braz J Microbiol 41(1):173-178

Badoei-Dalfard A (2016) L-asparaginase production in the Pseudomonas pseudoalcaligenes strain JHS-71 isolated from Jooshan Hot-spring. Mol Biol Res Commun 5(1):1-10

Bahrani MHAA (2016) Study the optimum parameters for production of cloned L-asparaginase type I by Escherichia coli. Int J Curr Microbiol Appl Sci 5(8):479-485

Bansal S, Srivastava A, Mukherjee G, Pandey R, Verma AK, Mishra P, Kundu B (2012) Hyperthermophilic asparaginase mutants with enhanced substrate affinity and antineoplastic activity: structural insights on their mechanism of action. FASEB J 26(3):1161-1171

Barry E, DeAngelo DJ, Neuberg D, Stevenson K, Loh ML, Asselin BL, Barr RD, Clavell LA, Hurwitz CA, Moghrabi A (2007) Favorable outcome for adolescents with acute lymphoblastic leukemia treated on Dana-Farber Cancer Institute acute lymphoblastic leukemia consortium protocols. J Clin Oncol 25(7):813-819

Batool T, Makky EA, Jalal Muna, Yusoff Mashitah M (2016) A comprehensive review on L-asparaginase and its applications. Appl Biochem Biotechnol 178(5):900-923

Bodey GP, Hewlett JS, Coltman CA, Rodriguez V, Freireich EJ (1974) Therapy of adult acute leukemia with daunorubicin and $\mathrm{L}$-asparaginase. Cancer 33(3):626-630

Boyse EA, Old LJ, Campbell HA, Mashburn LT (1967) Suppression of murine leukemias by L-asparaginase: incidence of sensitivity among leukemias of various types: comparative inhibitory activities of guinea pig serum L-asparaginase and Escherichia coli L-asparaginase. J Exp Med 125(1):17-31

Campbell H, Mashburn L (1969) L-asparaginase EC-2 from Escherichia coli some substrate specificity characteristics. Biochemistry 8(9):3768-3775

Cavanna M, Celle G, Dodero M, Picciotto A, Pannacciulli I, Brambilla G (1976) Comparative experimental evaluation of immunodepressive and toxic effects of L-asparaginase (NSC-109229) from Escherichia coli and from Erwinia carotovora. Cancer Treat Rep 60(3):255-257

Dash C, Mohapatra SB, Maiti PK (2016) Optimization, purification, and characterization of L-asparaginase from Actinomycetales bacterium BkSoiiA. Prep Biochem Biotechnol 46(1):1-7

Deokar VD, Vetal MD, Rodrigues L (2010) Production of intracellular L-asparaginase from Erwinia carotovora and its statistical optimization using response surface methodology (RSM). Int J Chem Sci 1:25-36

Diep TB, Thom NT, Sang HD, PhuongThao H, Van Binh N, Thuan TB, Vo THL, Quynh TM (2017) Screening streptomycin resistant mutations from gamma ray irradiated Bacillus subtilis B5 for selection of potential mutants with high production of protease. VNU J Sci Nat Sci Technol 32(1S):16-19

Doriya K, Kumar DS (2016) Isolation and screening of L-asparaginase free of glutaminase and urease from fungal sp. Biotech 6(2):239

El-Hefnawy MAA, Attia M, El-Hofy ME, Ali Shymaa M A (2015) Optimization Production of $L$ asparaginase by locally isolated filamentous fungi from Egypt. Curr Sci Int 4(3):330-341

El-Mched F, Olama Z, Holail H (2015) Purification and characterization of L-asparaginase from soil isolate under solid state fermentation. Int Res Pure Appl Phys 3(1):30-43

El-Sabbagh SM, El-Batanony NH, Salem TA (2013) L-asparaginase produced by Streptomyces strain isolated from Egyptian soil: purification, characterization and evaluation of its anti-tumor. Afr J Microbiol Res 7(50):5677-5686

Elshafei AM, Hassan MM, Abd M, Abouzeid E, Mahmoud DA, Elghonemy DH (2012) Purification, characterization and antitumor activity of L-asparaginase from Penicillium brevicompactum NRC 829. Br Microbiol Res 2(3):158-174

Frost J (2013) Multiple regression analysis: use adjusted R-squared and predicted R-squared to include the correct number of variables. The Minitab Blog. http://blog.minitab.com/blog/adventures-in-statistics/ multiple-regessionanalysis-use-adjusted-r-squared-and-predicted-r-squar ed-to-include-the-correctnumber-of-variables 
Gurunathan B, Sahadevan R (2011) Production of L-asparaginase from natural substrates by Aspergillus terreus MTCC 1782: optimization of carbon source and operating conditions. Int J Chem React Eng. https://doi. org/10.1515/1542-6580.2479

Han S, Jung J, Park W (2014) Biochemical characterization of L-asparaginase in $\mathrm{NaCl}$-tolerant Staphylococcus sp. OJ82 isolated from fermented seafood. J Microbiol Biotechnol 24(8):1096-1104

Hoe PCK, Khairuddin AR, Halimi MS (2016) A review on microbial mutagenesis through gamma irradiation for agricultural applications. JSNM 28(2):20-29

Huma T, Rashid MH, Javed MR, Ashraf A (2012) Gamma ray mediated mutagenesis of Phialocephala humicola: effect on kinetics and thermodynamics of a-amylase production. Afr J Microbiol Res 6(22):4639-4646

Hyster TK, Ward TR (2016) Genetic optimization of metalloenzymes: enhancing enzymes for non-natural reactions. Angew Chem Int Ed 55(26):7344-7357

Izadpanah QF, Javadpour S, Malekzadeh K, Tamadoni Jahromi S, Rahimzadeh M (2014) Persian gulf is a bioresource of potent L-asparaginase producing bacteria: isolation \& molecular differentiating. Int J Environ Res 8(3):813-818

Jain R, Zaidi K, Verma Y, Saxena P (2012) L-asparaginase: a promising enzyme for treatment of acute lymphoblastic leukiemia. PJSR 5(1):29-35

Jayaramu M, Hemalatha N, Rajeshwari C, Siddalingeshwara K, Mohsin S, Sunil Dutt PLNSN (2010) A novel approach for detection, confirmation and optimization of L-asparaginase from Emericella nidulans. Curr Pharm Res 1(1):20

Jones DT, Taylor WR, Thornton JM (1992) The rapid generation of mutation data matrices from protein sequences. Comput Appl Biosci 8(3):275-282

Joseph B, Rajan S (2011) L-lysine alpha oxidase from fungi as an anti tumor enzyme agent. Adv Biotechnol 10(8):27-30

Kavitha A, Vijayalakshmi M (2010) Optimization and purification of L-asparaginase produced by Streptomyces tendae TK-VL_333. Z Naturforsch C 65(7-8):528-531

Kolaskar A, Tongaonkar PC (1990) A semi-empirical method for prediction of antigenic determinants on protein antigens. FEBS Lett 276(1-2):172-174

Krishnapura PR, Belur PD, Subramanya S (2016) A critical review on properties and applications of microbial L-asparaginases. Crit Rev Microbiol 42(5):720-737

Kumar S, Dasu W, Pakshirajan K (2011) Purification and characterization of glutaminase-free L-asparaginase from Pectobacterium carotovorum MTCC 1428. Bioresour Technol 102(2):2077-2082

Kumar S, Stecher G, Michael L, Knyaz C, Tamura K (2018) MEGA X: molecular evolutionary genetics analysis across computing platforms. Mol Biol Evol 35(6):1547-1549

Lay H, Ekert H, Colebatch J (1975) Combination chemotherapy for children with acute lymphocytic leukemia who fail to respond to standard remission-induction therapy. Cancer 36(4):1220-1222

Mahajan RV, Saran S, Kameswaran K, Kumar V, Saxena R (2012) Efficient production of L-asparaginase from Bacillus licheniformis with low-glutaminase activity: optimization, scale up and acrylamide degradation studies. Bioresour Technol 125:11-16

Mahajan RV, Kumar V, Rajendran V, Saran S, Ghosh PC, Saxena RK (2014) Purification and characterization of a novel and robust L-asparaginase having low-glutaminase activity from Bacillus licheniformis: in vitro evaluation of anti-cancerous properties. PLoS ONE. https://doi.org/10.1371/journ al.pone.0099037

Mashburn LT, Wriston JC (1963) Tumor inhibitory effect of L-asparaginase. Biochem Biophys Res Commun 12(1):50-55

Matsumoto T, Sugano M (2013) 16S rRNA gene sequence analysis for bacterial identification in the clinical laboratory. Jpn J Clin Pathol 61(12):1107-1115

Maysa EM, Gamal Eldeen AM, EL Sayed ST (2010) Production, immobilization and anti-tumor activity of L-asparaginase of Bacillus sp R36. J Am Sci 6(8):157-165
Megavarnam AK, Janakiraman S (2015) Optimization of physiological growth conditions for maximal production of L-asparaginase by Fusarium species. Int J Bioassays 4(10):4369-4375

Michalska K, Jaskolski M (2006) Structural aspects of L-asparaginases, their friends and relations. Acta Biochim Pol 53(4):627

Murali $\mathrm{T}$ (2011) L-asparaginase from marine derived fungal endophytes of seaweeds. Mycosphere 2(2):147-155

Pansuriya RC, Singhal RS (2011) Effects of dissolved oxygen and agitation on production of serratiopeptidase by Serratia marcescens NRRL B-23112 in stirred tank bioreactor and its kinetic modeling. J Microbiol Biotechnol 21(4):430-437

Persson E, Halle B (2008) Cell water dynamics on multiple time scales. Proc Natl Acad Sci USA 105(17):6266-6271

Pradhan B, Dash S, Sahoo S (2013) Optimization of some physical and nutritional parameters for the production of L-asparaginase by isolated thermophilic Pseudomonas aeruginosa strain F1. Biosci Biotech Res Asia 10:389-395

Prakasham RS, Subba Rao C, Sreenivas Rao R, Suvarna Lakshmi G, Sarma PN (2007) L-asparaginase production by isolated Staphylococcus sp.-6A: design of experiment considering interaction effect for process parameter optimization. J Appl Microbiol 102(5):1382-1391

Rice P, Longden I, Bleasby A (2000) EMBOSS: the European molecular biology open software suite. Trends Genet 16(6):276-277

Roberts J, Prager MD, Bachynsky N (1966) The antitumor activity of Escherichia coli L-asparaginase. Cancer Res 26(10):2213-2217

Sakr M, Aboulwafa M, Aboshanab K, Hassouna N (2014) Screening and preliminary characterization of quenching activities of soil bacillus isolates against acyl homoserine lactones of clinically isolated Pseudomonas aeruginosa. Malays J Microbiol 10:80-91

Shechtman $\mathrm{O}$ (2013) The coefficient of variation as an index of measurement reliability. In: Methods of clinical epidemiology, Springer, pp 39-49

Sinha R, Singh HR, Jha SK (2013) Microbial L-asparaginase: present and future prospective. Int J Innov Res Sci Eng 2(11):7031-7051

Sooch BS, Kauldhar BS (2013) Influence of multiple bioprocess parameters on production of lipase from Pseudomonas sp. BWS-5. Braz Arch Biol Technol 56(5):711-721

Straight PD, Fischbach MA, Walsh CT, Rudner DZ, Kolter R (2007) A singular enzymatic megacomplex from Bacillus subtilis. Proc Natl Acad Sci USA 104(1):305-310

Varalakshmi V, Raju JK (2013) Optimization of L-asparaginase production by Aspergillus terreus mtcc 1782 using bajra seed flour under solid state fermentation. Int J Res Eng Technol 2(09):121-129

\section{Publisher's Note}

Springer Nature remains neutral with regard to jurisdictional claims in published maps and institutional affiliations.

\section{Submit your manuscript to a SpringerOpen ${ }^{\circ}$ journal and benefit from:}

- Convenient online submission

- Rigorous peer review

- Open access: articles freely available online

- High visibility within the field

- Retaining the copyright to your article

Submit your next manuscript at $\mathbf{s p r i n g e r o p e n . c o m ~}$ 